\title{
Los arreglos institucionales pendientes y las relaciones intergubernamentales en el federalismo fiscal argentino $\left.{ }^{*}\right)$
}

\section{POR MARCELO BERNAL(**) Y VALERIA BIZARRO(***)}

\begin{abstract}
Sumario: I. Introducción.- II. Federalismo fiscal y relaciones intergubernamentales.- III. El acuerdo fiscal federal y la distribución de competencias tributarias Nación-provincias en la reforma constitucional de 1994.- IV. Las relaciones fiscales provincia-municipios en el federalismo subnacional argentino.- V. Consideraciones finales.VI. Bibliografía.
\end{abstract}

Resumen: el objetivo del presente trabajo es analizar las principales características del federalismo fiscal argentino a partir de la reforma constitucional de 1994. Para ello, analizaremos las bases del diseño federal emergente, el reparto de competencias tributarias y el estado de situación del vínculo Nación-provincias, ponderando la ausencia de un acuerdo fiscal federal en los términos establecidos

$(*)$ Las consideraciones aquí vertidas provienen del trabajo y de la producción de dos equipos de investigación que trabajan temas de federalismo, gobierno multinivel y relaciones intergubernamentales (RIG) en la Universidad Nacional de Córdoba y la Universidad Siglo XXI.

(**) Abogado, Universidad Nacional de Córdoba. Magister en Relaciones Internacionales, Centro de estudios avanzados, Universidad Nacional de Córdoba. Magister en Gestión Pública Local, Universidad Carlos III, Madrid. Doctor en Derecho, Universidad Nacional de Cuyo. Prof. Facultad de Derecho y Facultad de Ciencias Económicas, Universidad Nacional de Córdoba y Universidad Siglo XXI.

(***) Abogada, Universidad Nacional de Córdoba. Doctoranda en Administración y Políticas Públicas, Instituto de Investigación y Formación en Administración Pública, Universidad Nacional de Cuyo (IIFAP-UNC). Becaria doctoral del Consejo Nacional de Ciencia y Tecnología (CONICET) con Lugar de Trabajo en el Centro de Investigaciones Jurídicas Sociales de la Facultad de Derecho - UNC, CONICET. 
por la Constitución Nacional. Posteriormente analizaremos las relaciones y vínculos intergubernamentales entre las provincias y sus municipios, tomando como dimensiones analíticas: tipo y nivel de reconocimiento de la autonomía municipal en las Constituciones Provinciales; características de los mecanismos de coordinación fiscal en las Constituciones Provinciales, las leyes orgánicas municipales y las leyes de coparticipación en cada provincia; el porcentaje de recursos coparticipables, como indicador del grado de autonomía con que cuentan los municipios; y las características y la relevancia de las oficinas técnicas del gobierno provincial destinadas a coordinar políticas con los gobiernos locales.

Palabras claves: federalismo - relaciones intergubernamentales - coordinación intergubernamental

\section{The outstanding institutional arrangements and intergovernmental relations in argentine fiscal federalism}

Abstract: in this paper, we are going to analyze the main characteristics of argentine fiscal federalism that has emerged after the constitutional reform in 1994. For that, we are going to examine the foundations of the emerging federal design, the new distribution of fiscal competences that has resulted from the last constitutional reform and the characteristics of Nation - provinces relation in Argentine, in the context of an absent fiscal federal agreement. Secondly, in order to analyze and describe the fiscal relations between the 23 argentine provinces with their local governments, we are going to use some significant dimensions: Type and level of municipal autonomy recognition in the Provincial Constitutions; characteristics of fiscal coordination mechanisms in provincial constitutions, municipal organic laws and co-participation laws in each province; Fiscal co-participation proportions, as an autonomy degree indicator that the local governments have; and, Characteristics and relevance of provinces technical offices that are used to coordinate actions with local governments.

Keywords: federalism - intergovernmental relations - intergovernmental coordination

\section{Introducción}

La principal característica de nuestro federalismo es la asimetría entre sus componentes. En un territorio extenso y disparmente poblado, los cinco gobiernos centrales de la denominada "Pampa húmeda" (Buenos Aires, CABA, Córdoba, Santa Fe y Entre Ríos) concentran alrededor del sesenta y cinco por ciento de la población y similar porcentaje del PBI. Las dieciocho provincias menos pobladas del país - de manera agregada - apenas equiparan en población a la provincia 
de Buenos Aires, la mayor de todas(1). Tales asimetrías demográficas se reproducen en similar medida en términos de desarrollo industrial, infraestructura vial y energética, oportunidades de empleo, acceso a bienes culturales y otros indicadores vinculados con el desarrollo socioeconómico, tales como salud o educación (Bernal, 2018, p. 274).

Con la reforma constitucional de 1994, que constituye uno de los hitos más trascendentes de la historia reciente del país, se buscó a partir de los diferentes preceptos normativos una acentuación de la descentralización del poder (Hernández, 2009, p. 41). Asimismo, una necesaria modernización del sistema de derechos y garantías y del modelo de división y equilibrio de poderes.

Así, el texto constitucional logra significativos avances en materias tales como:

a) la jerarquización del derecho internacional, y en particular, aquel derivado de los principales acuerdos en materia de derechos humanos aprobados por el Congreso Nacional; b) una fuerte ampliación de los derechos y garantías; c) la revisión del modelo de división y equilibrio de poderes preexistentes y la creación de numerosos organismos de control y seguimiento cruzado de la actividad de los poderes estatales; d) un intento de limitación del presidencialismo; e) un capítulo federal que reconoce nuevos niveles autónomos de gobierno, reparando históricos desajustes en la materia; y f) una redistribución del esquema de competencias federales, específicamente en materia fiscal (Bernal, 2018, p. 278).

Además, a partir de la reforma, podemos decir que coexisten cuatro órdenes o niveles de gobierno: 1) el gobierno federal, al que la ley suprema destina el título primero, "Gobierno Federal", artículos 44 a 120 de la segunda parte; 2) los gobiernos de provincia, regulados en el título segundo, "Gobiernos de provincia", artículos 121 a 128 de la segunda parte; 3) el gobierno autónomo de la Ciudad de Buenos Aires, artículo 129, en el título segundo de la segunda parte, que tiene naturaleza de ciudad-estado, distinta de las provincias y municipios; y 4) los gobiernos municipales que cuentan con autonomía en el orden institucional, político, administrativo, económico y financiero, según lo dispuesto por los artículos 5 y 123 de la Constitución Nacional (CN).

Junto con los cuatro órdenes o niveles de gobierno reconocidos aparece en la CN un nuevo instituto que va en la misma línea de fortalecimiento del federalismo. Se trata de la posibilidad conferida a las provincias - en el artículo 124de conformar regiones para impulsar el desarrollo económico y social, como así

(1) Datos del Censo de Población 2010. Fuente: INDEC. 
también establecer órganos con facultades para el cumplimiento de sus fines. La regionalización representa una "posible construcción de proyectos colectivos que potencien las energías latentes en nuestras unidades territoriales, y las proyecten de manera comunitaria para que cobren un peso diferente en los debates nacionales, e incluso, para que trasnacionalicen su presencia económica y comercial" (Bernal, 2018, p. 280).

Específicamente, en materia de distribución de competencias la cláusula constitucional corresponde al texto originario de 1853 y se encuentra en el actual artículo 121 (cláusula residual). El artículo determina que "las provincias conservan todo el poder no delegado por esta Constitución al Gobierno federal, y el que expresamente se hayan reservado por pactos especiales al tiempo de su incorporación". Dicha cláusula se complementa con los artículos 5(2)y 122(3) que determinan los alcances y límites de la autonomía de las provincias. Con respecto a la nueva distribución de competencias, se mantiene el sistema de distribución entre los poderes conservados por las provincias de manera ilimitada y los poderes delegados al gobierno federal de manera expresa o implícita, es decir, limitados. La tipología adoptada avanza decididamente hacia "la devolución de competencias" (Bidart Campos, 1996, p. 445), trayectoria seguida por la mayoría de los países con gobiernos federativos o en vías de descentralización.

Por lo anterior, el nuevo diseño federal implica una mayor complejidad de las dimensiones políticas e institucionales del Estado federal, que dan lugar a un gobierno multinivel moderno y complejo, que busca dar respuesta a desafíos actuales y futuros. La reforma constitucional sentó las bases para la configuración de un diseño federal de bases cooperativas, basado en principios como la coordinación, la solidaridad y el desarrollo homogéneo y equilibrado del territorio.

Frente a dicho panorama nos planteamos dos interrogantes: ¿qué ha sucedido, entonces, en veintiséis años para que el capítulo federal sea hoy una promesa incumplida? ¿Por qué existe una relación de tensión tan grande entre el texto de la norma y la realidad? Con respecto a tales cuestionamientos, existen dos aspectos cruciales que, consideramos, cristalizan el fracaso de la promesa de la reforma constitucional y condicionan el surgimiento de los nuevos arreglos institucionales.

(2) “Cada provincia dictará para sí una Constitución bajo el sistema representativo republicano, de acuerdo con los principios, declaraciones y garantías de la Constitución Nacional; y que asegure su administración de justicia, su régimen municipal, y la educación primaria. Bajo de estas condiciones el Gobierno federal, garante a cada provincia el goce y ejercicio de sus instituciones" (artículo 5 de la $\mathrm{CN})$.

(3) "Se dan sus propias instituciones locales y se rigen por ellas. Eligen sus gobernadores, sus legisladores y demás funcionarios de provincia, sin intervención del Gobierno federal” (artículo 122 de la CN). 
El primero y más relevante es la ausencia de un pacto fiscal federal aprobado en los términos propuestos por la $\mathrm{CN}$, que desnuda las precarias bases del nuevo diseño federal a todas luces incompleto. Al no haberse generado los consensos necesarios para dar sanción a una ley-convenio de coparticipación, nos regimos por una antigua norma de 1988 y por una serie de instrumentos multilaterales a los que la Corte Suprema de Justicia de la Nación (CSJN) ha dado en llamar derecho intrafederal (4).

El segundo aspecto, en materia de vínculos intergubernamentales, es que en la actualidad nuestro federalismo cuenta con una muy baja densidad de normas, instituciones y procesos que lleven adelante la gestión asociada de los temas comunes entre el gobierno federal y los de las provincias, y de estas con sus municipios, lo que se traduce en un infradesarrollo notable de las relaciones intergubernamentales (RIG) (tanto verticales como horizontales). Las relaciones existentes son escasas, priman en ellas las bajas capacidades técnicas de las burocracias especializadas y están basadas en vínculos asimétricos, tanto en el eje Naciónprovincias, como en el eje provincias-municipios. Estos déficits institucionales y sus implicancias en la materia fiscal constituyen hilos conductores que serán abordados a lo largo del presente trabajo.

\section{Federalismo fiscal y relaciones intergubernamentales}

Coincidimos con un clásico de los estudios federales, Carl J. Friedrich (1968), quien afirma que no se puede hablar de federalismo en singular, ya que todo Estado federal cuenta con características y singularidades que lo vuelven único. Por ello, se sostiene la conveniencia de hablar de federalismos - en plural- puesto que todo federalismo es el resultado de un proceso en el que intervienen factores históricos, geográficos, culturales, étnicos, religiosos, etc., que brindan fisonomías específicas a cada modelo estatal.

Sin embargo, y más allá de la heterogeneidad que caracteriza a todos los federalismos, creemos que es posible afirmar que existe un conjunto de elementos constitutivos de un sistema de Estado federal, tales como: a) la presencia de una norma escrita fundamental en donde se determinan la distribución de competencias y atribuciones entre los diferentes niveles de gobierno; b) dicho texto liminar no puede modificarse unilateralmente por alguna de las partes; c) en el sistema de división de poderes existe habitualmente una cámara legislativa orientada a defender los intereses de los gobiernos subnacionales autónomos (Senado o similares) y un órgano jurisdiccional con competencia originaria en la materia federal

(4) Entendido como aquella rama del derecho que regula las relaciones tributarias entre los distintos niveles de gobierno a los fines de evitar las dobles o múltiples imposiciones. 
(Cortes Supremas o Tribunales Constitucionales); d) en todos ellos rige un acuerdo fiscal federal que determina las funciones y competencias a desempeñar por cada uno de los niveles de gobierno y los recursos; y e) un conjunto de normas, procesos e instituciones que llevan adelante la gestión de los servicios o las políticas públicas comunes y compartidas.

Estos tres últimos elementos (normas, procesos e instituciones) componen un moderno campo disciplinar, el estudio de las RIG. Estas comprenden los vínculos de coordinación, cooperación, apoyo mutuo, e intercambio de acciones que se dan entre dos o más órdenes o niveles de gobierno y forman parte de los procesos de gestión política como modalidades de un esfuerzo de armonización, cooperación, compatibilización y negociaciones contratadas, acordadas, convenidas o concertadas (Pontifes Martínez, 2002, p. 51).

El federalismo en su dimensión fiscal permite estudiar el modo en el que los diferentes niveles del Estado reparten las competencias, los servicios a su cargo y los recursos tributarios para llevar adelante las funciones que son propias y naturales a cada uno de ellos. Desde la perspectiva de las finanzas públicas, el federalismo fiscal se ocupa de estudiar cómo hay que distribuir (análisis normativo) y cómo se distribuyen (análisis positivo) las responsabilidades de gasto y las facultades impositivas entre distintos niveles de gobierno. Tales aspectos tienen una importancia económica-financiera, pues los arreglos que existen pueden afectar la eficiencia con la cual la gestión estatal es realizada, y tienen también trascendencia política, pues los arreglos particulares pueden implicar altos grados de concentración del poder en el gobierno central o, en la alternativa opuesta, comunidades locales con elevados grados de autonomía y participación política (Teijeiro, 2009, p. 3).

En Argentina, la última reforma constitucional importó un rediseño de las bases de nuestro federalismo fiscal. Adquiere centralidad la obligación impuesta al Congreso Nacional de dictar, antes de la finalización del año 1996, una ley-convenio de coparticipación, que debía ser aprobada con una mayoría absoluta del total de sus miembros y también tratada y aprobada por todas las legislaturas provinciales. Según el mandato constitucional, dicha ley-convenio de coparticipación debe contemplar criterios objetivos de reparto, dar prioridad al logro de un grado equivalente de desarrollo, calidad de vida e igualdad de oportunidades en todo el territorio nacional, y resultar equitativa y solidaria (artículo 75 inciso 2).

Las disposiciones precedentes procuraban dar lugar a un fuerte entramado de relaciones intergubernamentales verticales y horizontales que permitieran nuevos ámbitos de debate, de construcción de consensos generales y de articulación de políticas de mediano y largo plazo. No obstante, al presente no existe una leyconvenio sancionada con las características previstas por el texto constitucional. 
Este estado de situación es descripto por la CSJN en un reciente fallo (5) como un desajuste institucional grave a solucionar en el breve plazo. El inmovilismo de los socios federales para poner en marcha los arreglos institucionales emergentes de la reforma supone un delicado problema institucional dado el evidente conflicto entre el mandato del poder constituyente y la ausente voluntad de los poderes constituidos para sancionar un acuerdo fiscal federal definitivo.

\section{El acuerdo fiscal federal y la distribución de competencias tributarias Nación-provincias en la reforma constitucional de 1994}

Como expresamos, con la reforma constitucional se rediseñan aspectos centrales del federalismo argentino, especialmente en materia fiscal. Por un lado, se modifica la distribución de competencias tributarias entre Nación y provincias. Así, a la Nación le corresponde: a) el dictado de derechos de importación y exportación -impuestos aduaneros- en forma exclusiva (excluyente) y permanente (artículos 4, 75 inciso 1 y 126); b) los impuestos indirectos en competencia concurrente y de modo permanente con las provincias (artículo 75 inciso 2) y c) los impuestos directos en forma excepcional y por tiempo determinado (proporcionalmente iguales en todo el territorio de la Nación, siempre que la defensa, seguridad común y bien general del Estado lo exijan) (artículo 75 inciso 2). A las provincias le corresponden: a) los impuestos indirectos en competencia concurrente y permanente con la Nación (artículo 75 inciso 2) y b) los impuestos directos en forma exclusiva y permanente (artículo 75 inciso 2), salvo en los supuestos de excepción en los que pueden ser establecidos por la Nación.

Por otro lado, se establece la obligación para el Congreso Nacional del dictado de una ley-convenio de coparticipación antes de la finalización del año 1996 según la cláusula transitoria sexta. En cuanto a los requisitos constitucionales de forma de la futura ley-convenio, se exige que la misma tenga al Senado como cámara de origen, que sea sancionada con la mayoría absoluta de la totalidad de los miembros de la cámara, que no pueda ser modificada ni reglamentada unilateralmente y que sea aprobada por las 23 provincias y CABA. En cuanto a su contenido, debe erigirse en base a acuerdos celebrados previamente entre la Nación, provincias y CABA, instituir regímenes de coparticipación de los diferentes impuestos y garantizar la automaticidad de los fondos.

La distribución entre la Nación, provincias y CABA debe efectuarse en forma directa a las competencias, servicios y funciones de cada una de ellas, garantizando criterios objetivos de reparto. Por último, establece que deberá ser solidaria, equitativa y dar prioridad al logro de un grado equivalente de desarrollo, calidad

(5) Bazán, Fernando s/ Amenazas. CSJN, 4 de abril de 2019. 
de vida e igualdad de oportunidades en todo el territorio nacional. Dispone también dicha norma la creación de un Banco Federal con facultades de emisión de moneda y de un organismo de control de la coparticipación integrado por representantes de cada una de las provincias (artículo 75, incisos 2 y 6 ).

A casi veintiséis años de la reforma, aún no se ha dado cumplimiento a la cláusula constitucional. Dicha omisión e incumplimiento del acuerdo federal fiscal cristalizado en la reforma constitucional constituye el nudo de la mayor parte de los problemas de distribución y de reparto de competencias y recursos que afectan hoy al federalismo argentino.

La ausencia del dictado de una ley-convenio con las características señaladas contribuyó a una formidable concentración de recursos en el gobierno nacional. En virtud del régimen de coparticipación vigente, la facultad (concurrente) para el dictado de impuestos indirectos recae exclusivamente sobre la Nación, como así también la facultad respecto del dictado de contribuciones e impuestos directos, que es excepcional y condicionada para la Nación, pero en la realidad es ejercida por esta de manera sostenida e ininterrumpida a través del tiempo, operando una absoluta inversión de la regla, en desmedro de la potestad tributaria provincial.

El incumplimiento del mandato constitucional es suplido, en parte, por un antiguo régimen de coparticipación instaurado con la ley 23548 de 1988, como así también por una serie de pactos fiscales: Pacto Fiscal I(6), Pacto Fiscal II(7), los Compromisos Federales de 1999 y de 2000 (8), y el Consenso Fiscal de 2016 (9). Tales instrumentos fueron empleados como herramientas provisorias para acordar

(6) El denominado "Pacto Fiscal I" se celebró en 1992 e implicó un acuerdo entre el gobierno nacional y los gobiernos provinciales con miras a financiar las obligaciones previsionales nacionales. En la ocasión se consideró necesario detraer un porcentaje (15\%) de la masa coparticipable antes de proceder a su distribución, afectado específicamente a ese objetivo.

(7) En agosto de 1993 se celebró el llamado "Pacto Fiscal II", también denominado "Pacto Federal para el Empleo, la Producción y el Crecimiento", en virtud del cual se busca dar impulso a la economía nacional y la reactivación de las economías regionales. Por ello, la Nación y las provincias se comprometen, entre otras cosas, a derogar tributos que tienen incidencia en las actividades económicas, propender a la privatización de servicios prestados por las provincias y disminuir el costo laboral.

(8) Dentro de los llamados Compromisos Federales, encontramos el de diciembre de 1999, el "Compromiso Federal para el Crecimiento y la disciplina Fiscal" del año 2000.

(9) En virtud del cual la Nación, las provincias y la CABA se comprometen a: adherir a la Ley de Responsabilidad Fiscal; modificar la Ley de Impuesto a las Ganancias; aprobar la Ley de Revalúo Impositivo; prorrogar la vigencia del Impuesto sobre los créditos y débitos en cuentas bancarias; reformular y adecuar el esquema del impuesto sobre los combustibles líquidos y el gas natural; impulsar reformas sobre el régimen previsional; consensuar una nueva Ley de coparticipación federal; consensuar una nueva Ley de modernización del Estado, entre otros compromisos. 
la distribución de recursos y competencias tributarias. Todos ellos tuvieron como común denominador que se firmaron en escenarios de crisis económicas y en base a una agenda principalmente impuesta por el gobierno federal en base a recomendaciones de organismos multilaterales de crédito y en el marco del proceso de reforma del Estado. Tal conglomerado de normas y acuerdos parciales operan como soporte para los vínculos y relaciones intergubernamentales en la materia.

Paralelamente a ello, se profundizó, desde los años noventa, un proceso de descentralización de funciones y servicios hacia las provincias, lo que las transformó en responsables de ejecutar el $50 \%$ o más del gasto total por provisión de bienes y servicios. El resultado de la asimetría observada entre la descentralización de gastos y la recaudación de ingresos generó un importante desequilibrio vertical que, además de los recursos por coparticipación, requirió el envío por parte del gobierno nacional de un conjunto de transferencias, tanto de libre disponibilidad como condicionadas (Rezk; Padraja y Suárez Pandiello, 2011, p. 148).

Este proceso de devolución de competencias sin una adecuada transferencia de recursos financieros arrojó al país hacia un diseño fiscalmente centralizado con una cierta descentralización o desconcentración administrativa, junto con la consolidación del mecanismo de transferencias condicionadas, lo que significó un visible retroceso para los niveles subnacionales.

Especialmente, en términos de RIG, la reforma constitucional introdujo herramientas para facilitar la coordinación intergubernamental y dar paso a un "federalismo de concertación". Bajo esta denominación se configura un diseño de interrelación entre los distintos niveles de gobierno, en el cual prevalece la idea de una mayor relación y armonización de funciones que no se encuentran aisladas e inconexas unas de otras, por lo que deben ser coordinadas. Se debe acordar entre la Nación y las provincias - y entre las provincias entre sí- el desarrollo de las políticas intercomunales y la gestión intergubernamental de los asuntos e intereses comunes.

Sin embargo, Argentina experimenta un estadio de infradesarrollo de las modalidades de RIG que caracterizan a cualquier federalismo moderno. Los mecanismos de vinculación son casi exclusivamente verticales, con un eje que impone su preminencia desde arriba hacia abajo, al concentrar el gobierno nacional la mayor parte del poder recaudatorio.

Las escasas RIG verticales requieren un mayor énfasis en dinámicas más cooperativas y de coordinación, siendo a su vez necesaria la consolidación de múltiples modalidades de RIG horizontales entre las provincias, los municipios e incluso las propias regiones. 
Tales fenómenos, es decir, la ausencia de un acuerdo fiscal en los términos planteados a nivel constitucional y de un entramado de RIG que determinen los mecanismos y modalidades de interacción y cooperación entre niveles de gobierno, han provocado que las negociaciones entre gobiernos sean personalizadas. En efecto, el mayor poder negociador del gobierno federal ha empujado a muchas provincias a la firma de acuerdos desventajosos para sus distritos en el mediano y largo plazo, urgidos por necesidades financieras, de obra pública o de naturaleza política de corto plazo.

Este estado de situación que encontramos en el vínculo Nación-provincias es extensible a los vínculos entre las provincias, las que carecen de organismos de articulación horizontal como son en otras experiencias federales los consejos o asambleas de gobernadores.

\section{Las relaciones fiscales provincia-municipios en el federalismo subnacional argentino}

Como se mencionó en la introducción, la característica principal del federalismo argentino es su heterogeneidad. Por tal motivo, en esta sección del trabajo describimos y analizamos las RIG existentes entre Estados provinciales asimétricos y con múltiples y disímiles modalidades de organización del gobierno municipal.

En dicho sentido, hemos considerado prioritario el abordaje de las siguientes dimensiones analíticas:

a) Tipo y nivel de reconocimiento de la autonomía municipal en las Constituciones provinciales.

b) Características de los mecanismos de coordinación fiscal existentes en las leyes orgánicas municipales y de coparticipación en cada provincia.

c) Porcentaje de recursos coparticipables, como indicador del grado de autonomía con que cuentan los municipios.

d) Características y relevancia de las oficinas técnicas del gobierno provincial destinadas a coordinar políticas con los gobiernos locales.

A partir de estas cuatro dimensiones nos proponemos caracterizar los vínculos intergubernamentales existentes, a los fines de determinar si en ellos prima la institucionalización o la informalidad y las negociaciones personalizadas entre las partes. 


\section{IV.1. Tipo y nivel de reconocimiento de la autonomía municipal en las Constituciones provinciales}

El debate sobre el carácter autónomo o meramente autárquico de los municipios en Argentina es de vieja data, remontándose al texto de la Constitución originaria de 1853, en donde se reconoce el régimen municipal de gobierno sin profundizar acerca de sus alcances y límites. Desde aquella instancia remota tuvimos décadas de debates y tensiones sobre el tema, mediadas por una jurisprudencia de la CSJN refractaria al reconocimiento autonómico. Será desde el constitucionalismo provincial, y especialmente a partir de 1986, en donde numerosas reformas constitucionales provinciales receptan la autonomía municipal.

En 1989, la CSJN da un giro a su jurisprudencia con el fallo Rivademar(10), en donde analiza comparativamente las similitudes y diferencias entre los entes autárquicos y los municipios, dando finalmente reconocimiento al fenómeno autonómico local.

El convencional constituyente de 1994 recepta de manera definitiva el instituto, en una fórmula que abarca la dimensión institucional, política, administrativa, económica y financiera, dejando a las provincias la potestad de reglar su alcance y contenido. Esta última cláusula constitucional ha abierto la puerta a un heterogéneo reconocimiento y delimitación de la autonomía municipal (en sus modalidades plena o semiplena), mientras que relevantes distritos ni siquiera han incorporado el instituto.

De las 23 provincias del país, 20 reconocen la autonomía municipal en sus constituciones. De ellas, 17 han optado por un modelo de reconocimiento pleno de la autonomía municipal, difiriendo en matices con respecto al alcance y posibilidades de dicha figura. Otras 3 provincias (Salta, Neuquén y Chubut), en cambio, han adoptado un formato de autonomía semiplena o limitada, en donde la dimensión institucional de la autonomía se ve afectada por recortes, entre ellos, que las cartas orgánicas municipales deban ser aprobadas por las legislaturas provinciales. Finalmente, 3 distritos muy importantes (Mendoza, Santa Fe y Buenos Aires) no han actualizado sus constituciones provinciales por diferentes factores de política doméstica.

Ahora bien, por las fuertes asimetrías de tamaño y población existentes entre los diferentes estados provinciales, la mora de estas últimas tres provincias en incorporar la autonomía municipal es por demás significativa en el estudio del fenómeno autonómico, en la medida en que en estos 3 distritos residen el 51,22\% de

(10) CSJN, “Rivademar, Ángela Martínez Galván de c/ Municipalidad de Rosario”, 1989. 
la población del país. En los 17 que adoptan la autonomía municipal plena reside el 35,91\% de los habitantes, en los 3 con autonomía semi plena un exiguo 5,67\%, mientras que el 7,2\% restante reside en la Capital Federal, distrito con atribuciones autonómicas específicas y diferenciadas(11).

Es decir que más de la mitad de los habitantes del país reside en distritos en donde la autonomía municipal no rige de manera plena y efectiva. Siendo la provincia de Buenos Aires, por su magnitud, un factor fuertemente distorsivo a la hora del análisis de nuestro objeto de estudio.

\section{IV.2. Mecanismos de coordinación fiscal existentes en el federalismo subnacional argentino}

A los fines de la caracterización de los mecanismos de coordinación fiscal entre provincias y municipios en Argentina, resulta oportuno presentar los principales rasgos del diseño institucional en el cual se enmarcan las diferentes RIG.

De acuerdo con lo desarrollado en el apartado anterior, el reconocimiento constitucional por parte de las provincias de una autonomía municipal —en las dimensiones institucional, política, administrativa, y económica-financieraconstituye el puntapié inicial para generar vínculos intergubernamentales que no se tornen asimétricos, precarios o inestables. No obstante, el mero reconocimiento constitucional de la autonomía municipal no alcanza, es necesario dotarla de contenido.

El municipio, para poder desenvolverse con autonomía e independencia en el ejercicio de sus atribuciones, competencias y fines requiere del ejercicio de su potestad tributaria, entendida como aquella facultad para crear y percibir impuestos, tasas y contribuciones especiales, como competencia de naturaleza originaria.

Para lograr una adecuada caracterización de los mecanismos intergubernamentales de coordinación fiscal existentes en el federalismo subnacional argentino, seleccionamos dos factores que nos permiten contextualizar y comprender tales vínculos. En primer lugar, analizamos la distribución de títulos competenciales en materia tributaria entre provincias y municipios efectuada en las constituciones provinciales y leyes orgánicas municipales vigentes. En segundo lugar, examinamos en los textos constitucionales la existencia de lineamientos concretos destinados a regular las relaciones intergubernamentales en la materia económica-financiera, a partir del establecimiento de determinadas condiciones y

(11) Datos basados en el Censo de Población 2010 (Fuente INDEC). 
exigencias que hacen al diseño institucional y que brindan un marco a partir del cual operan dichos vínculos.

Del relevamiento surge que, de las 23 provincias argentinas, en 3 de ellas (Buenos Aires, Mendoza y Santa Fe) no existe un reconocimiento constitucional directo de la potestad tributaria local. En el caso de la constitución provincial de Buenos Aires, se establece que los títulos tributarios de los gobiernos locales serán definidos por ley y, a su vez, se fija una limitación o exigencia adicional para la creación o aumento de los recursos tributarios (12) por parte de los consejos deliberantes de los gobiernos locales. Por su parte, la ley orgánica de municipios solo reconoce dos categorías o especies tributarias (tasas y contribuciones especiales), las cuales no constituyen fuentes genuinas de financiamiento, precisamente por las notas tipificantes de su naturaleza tributaria. En la provincia de Santa Fe se observa una ausencia de reconocimiento expreso a la potestad tributaria local, aunque, de manera genérica, la ley orgánica municipal prevé el dictado de impuestos, tasas y contribuciones especiales compatibles con el régimen tributario provincial y federal. El caso más extremo es el de Mendoza, que no solo desconoce la potestad tributaria local, sino que prohíbe explícitamente en la constitución a sus gobiernos locales legislar en materia impositiva (artículo 199 inciso 6) y en la ley orgánica municipal establece la prohibición de dictar impuestos, quedando habilitados los municipios al dictado de tasas y contribuciones especiales por servicios efectivamente prestados.

Entre las provincias cuyas constituciones reconocen expresamente la autonomía municipal, identificamos diversos panoramas en relación a la distribución de competencias tributarias.

Por un lado, se encuentran aquellas en las que su constitución provincial menciona las categorías tributarias de competencia municipal de manera genérica, es decir, aludiendo a impuestos, tasas y contribuciones especiales o expresiones análogas, pero sin explicitar cuáles (Catamarca, Chaco, Chubut, Córdoba, Entre Ríos, La Pampa, Neuquén, Río Negro, San Juan, San Luis, Santiago del Estero y Tierra del Fuego). Por otro lado, aquellas que, además de la expresión genérica (impuestos, tasas y contribuciones especiales), establecen en su articulado alguna mención a un impuesto específico (por ejemplo, el dictado del impuesto inmobiliario, del automotor, o incluso de ambos, o bien la recaudación total o un porcentaje de recaudación de estos). Tal es el caso, de las provincias de Corrientes, Formosa, Jujuy, Misiones, Salta, Santa Cruz y Tucumán. Finalmente, en la provincia de La Rioja

(12) Todo aumento o creación de impuestos o contribución de mejoras, necesita ser sancionado por mayoría absoluta de votos de una asamblea compuesta por los miembros del Concejo Deliberante y un número igual de mayores contribuyentes de impuestos municipales (artículo 193, inciso 2). 
no se mencionan las categorías o especies tributarias que pueden dictar los municipios en la órbita de su jurisdicción, aunque el reconocimiento de la potestad tributaria surge del articulado.

En el caso de la distribución de competencias efectuadas en las leyes orgánicas municipales, observamos algo similar. En algunos casos, solo refieren de manera genérica las especies o categorías tributarias (Córdoba, Entre Ríos, Jujuy, La Rioja, Río Negro y Santa Cruz). En otros casos, la norma avanza: a) efectuando una definición más detallada de la materia imponible de los municipios (Catamarca, Chaco, Misiones, Neuquén, Salta, San Juan, San Luis y Santiago del Estero); b) haciendo mención al impuesto inmobiliario, al impuesto al automotor, o a ambos, o definiendo algún porcentaje de recaudación de aquellos (Chubut, Corrientes, Neuquén, San Luis, Santa Cruz, Tucumán); y c) estableciendo alguna limitación o exigencia adicional para el ejercicio de la potestad tributaria local en cuanto al proceso de sanción de las ordenanzas impositivas. En este último caso encontramos a aquellas provincias que exigen para su sanción el voto de una mayoría absoluta de los miembros (Misiones, Tierra del Fuego, La Pampa - la cual además exige la conformidad del poder ejecutivo local-). Como caso extremo, la provincia de Formosa dispone que la iniciativa de ordenanzas impositivas corresponde exclusivamente al departamento ejecutivo provincial (artículo 80), en clara vulneración del principio de legalidad de raigambre constitucional y que rige en la materia tributaria.

En cuanto a la existencia de lineamientos concretos destinados a regular las RIG en materia económica-financiera en las constituciones provinciales, aquí también el panorama es heterogéneo.

Entre las constituciones que no receptan lineamientos de ningún tipo encontramos el caso de Buenos Aires, Mendoza, Santa Fe y Catamarca, que dejan librada la regulación de los mecanismos de coparticipación y distribución de recursos a las leyes orgánicas municipales y leyes de coparticipación provincial específicas.

Entre las constituciones que receptan o fijan algún lineamiento encontramos diversos matices que manifiestan tomas de posición en cuanto a la forma en que se conciben los vínculos intergubernamentales. Así, tenemos provincias que solo mencionan la necesidad de establecer una ley o régimen de coparticipación (Chaco, Chubut, La Pampa, Salta) y provincias que explícitamente ponen el acento en el modo de efectuarse la distribución de los recursos: a) atendiendo a las competencias, funciones y servicios (Entre Ríos, La Rioja, Neuquén, San Luis, Santa Cruz, Santiago del Estero); b) fijando un monto de distribución primaria mínimo (Corrientes y Santiago del Estero); c) estableciendo particularidades en cuanto a la forma y el tiempo de percepción de los recursos (Jujuy, La Pampa, Misiones, 
Tucumán); y d) destacando particularidades que deberán ser tenidas en cuenta en los criterios de reparto (San Juan y San Luis).

Otro aspecto relevante es el acento que ponen algunas constituciones provinciales en que estas leyes o regímenes de coparticipación de recursos surjan, o se enmarquen, en un convenio o acuerdo concertado entre la provincia y los municipios (Córdoba, Corrientes, Jujuy, Neuquén y Río Negro). Y, en el sentido opuesto, ubicamos, nuevamente, el caso de la provincia de Formosa, donde solo prevé como atribución del poder legislativo provincial el establecimiento de la participación de los municipios en los regímenes de coparticipación.

El panorama descripto constituye el marco institucional a partir del cual —con un mayor o menor grado de discrecionalidad- se desenvuelven en el país los vínculos intergubernamentales provincias-municipios en materia fiscal.

Por último, a partir del relevamiento efectuado en las leyes orgánicas municipales y leyes de coparticipación, identificamos escasos supuestos en donde se institucionaliza alguna instancia o mecanismo de coordinación en materia fiscal.

En el caso de Catamarca se crea, a partir de la ley de coparticipación provincial, la Comisión de Participación Municipal. Esta verifica la determinación de las asignaciones y distribuciones, las liquidaciones y transferencias, controla la información y rendición de cuentas, el cumplimiento de las obligaciones establecidas en la ley y propone las medidas que considere conducentes para la aplicación de la ley y del régimen municipal. La Ley de coparticipación de San Luis prevé una Comisión Fiscal Provincial. Dicha Comisión debe coordinar las pautas presupuestarias con los municipios, las ordenanzas tributarias municipales, las tareas de fiscalización tributaria y cualquier otra función de coordinación financiera y fiscal.

En el extremo opuesto, destacamos dos casos en donde directamente no se prevé la participación de gobiernos locales. Tal es el caso de La Rioja, cuya ley de coparticipación instituye la Comisión de trabajo para la fiscalización y seguimiento de los recursos a recaudar y coparticipar, sin prever la participación de ninguna autoridad municipal; y el caso de Río Negro con la Comisión Permanente de Aplicación y Arbitraje. La Comisión Permanente entiende en todo lo atinente a la distribución secundaria de regalías y entre sus funciones tiene la posibilidad de incluir o excluir gobiernos locales del listado de municipios productores que reciben un 35\% en la distribución secundaria de regalías hidrocarburíferas.

En resumen, podemos afirmar que las instancias de coordinación de RIG en materia fiscal entre las provincias y los municipios argentinos son escasas, insuficientes y heterogéneas. Esta precariedad o ausencia de vínculos formales conduce a canalizar estas relaciones a través de mecanismos informales y, por ello, 
asimétricos y discrecionales (entendiendo al concepto como no atado a marcos normativos).

\section{IV.3. Porcentaje de recursos coparticipables como indicador del grado de autonomía con que cuentan los municipios}

Nos resulta de interés incorporar al análisis el porcentaje que los gobiernos provinciales destinan a sus municipios (distribución primaria) de los recursos que les transfiere la Nación en base al régimen de coparticipación federal vigente, previsto por la ley $23548 / 88$. Si bien cada provincia coparticipa de manera diferente sus tributos provinciales internos - con mayores o menores grados de desconcentración-, el porcentaje de la coparticipación federal nos permite percibir claramente la heterogeneidad del sistema y las asimetrías existentes entre las diferentes jurisdicciones. Las diferencias porcentuales deben ser entendidas como condicionantes a la hora de analizar el grado de dependencia o de autosuficiencia financiera de los gobiernos municipales. Se traducen también en limitaciones para el desarrollo de sus capacidades autonómicas.

\section{IV.3.1. Cuadro: porcentajes de recursos coparticipables (distribución primaria entre provincias-municipios)}

\begin{tabular}{|l|l|l|l|}
\hline \multicolumn{1}{|c|}{ Provincia } & \multicolumn{1}{|c|}{$\begin{array}{c}\text { Porcentaje } \\
\text { coparticipable }\end{array}$} & \multicolumn{1}{|c|}{ Provincia } & \multicolumn{1}{c|}{$\begin{array}{c}\text { Porcentaje } \\
\text { coparticipable }\end{array}$} \\
\hline Buenos Aires & $16,14 \%$ & Misiones & $12 \%$ \\
\hline Catamarca & $25 \%$ & Neuquén & $15 \%$ \\
\hline Chaco & $15,50 \%$ & Río Negro & $13 \%$ \\
\hline Chubut & $11 \%$ & Salta & $15 \%$ \\
\hline Córdoba & $20 \%$ & San Juan & $14,5 \%$ \\
\hline Corrientes & $19 \%$ & San Luis & Variable. Actual $8 \%$ \\
\hline Entre Ríos & Variable. $15,32 \%$ & Santa Cruz & $11 \%$ \\
\hline Formosa & $12 \%$ & Santa Fe & Variable. Actual 14\% \\
\hline Jujuy & $17 \%$ & Santiago del Estero & $15 \%$ \\
\hline La Pampa & $11 \%$ & Tierra del Fuego & $25 \%$ \\
\hline La Rioja & $15 \%$ & Tucumán & $16,50 \%$ \\
\hline Mendoza & $18,8 \%$ & Promedio nacional & $\mathbf{1 5 , 4 2 \%}$ \\
\hline
\end{tabular}

Fuente: elaboración propia a partir de los regímenes provinciales de coparticipación vigentes.

De los datos comparados se puede comprobar que existen fuertes diferencias entre las provincias que menos recursos de la coparticipación federal distribuyen a sus municipios (San Luis, Chubut, La Pampa, Santa Cruz) y las que más recursos disponen a tal efecto (Catamarca, Tierra del Fuego, Córdoba, Mendoza). La brecha llega a alcanzar una relación de 3 a 1 en los casos extremos, desnudando fuertes 
disparidades que impactan en los niveles de autonomía local y configuran un límite a la viabilidad financiera de los Estados municipales, constreñidos a convivir con la tensión existente entre la demanda de servicios por parte de la ciudadanía y la estrechez financiera. El promedio obtenido de un $15,42 \%$, por su parte, parece acotado teniendo en cuenta las crecientes demandas de bienes y servicios públicos existentes a nivel municipal.

Debe añadirse que muchas provincias tienden a compensar o disminuir dichos porcentajes en base a criterios propios de distribución de las competencias tributarias en cada nivel de gobierno y a las alícuotas de los tributos internos existentes que se coparticipan entre ambos, por lo que podemos afirmar que allí la heterogeneidad es aún más amplia.

Finalmente, otro dato de interés es que, a partir de 2018, el conjunto de las provincias argentinas cuenta con una ley convenio de coparticipación provincia-municipios, o con un régimen constitucional de distribución de recursos y alícuotas de sus tributos coparticipables. El ciclo se cierra con las recientes sanciones de leyes convenios por parte de las provincias de La Rioja y San Juan, siendo el mismo un indicador de calidad institucional que el gobierno federal y las provincias no han podido emular hasta la fecha.

\section{IV.4. Características y relevancia de las oficinas técnicas del gobierno provincial destinadas a coordinar políticas con los gobiernos locales}

En esta última dimensión de análisis se busca identificar en la gestión provincial la existencia y, en su caso, jerarquía, de las oficinas gubernamentales destinadas a vincular técnicamente al gobierno provincial y sus municipios y, por último, establecer si en ellos se identifican mecanismos de cooperación y coordinación intergubernamentales o, de lo contrario, si las políticas son definidas y planificadas desde el gobierno provincial (top down) sin la participación de los gobiernos locales.

A los fines de dar respuesta a ese interrogante, se llevó a cabo un relevamiento de los sitios web oficiales del conjunto de los gobiernos provinciales y de las diferentes leyes de ministerios provinciales (13). El relevamiento aporta datos de mucho interés, aunque en algunas provincias el acceso a la información pública disponible es escaso y/o de baja calidad.

Ninguna de las provincias argentinas ha considerado otorgar rango ministerial a la tarea de coordinación de políticas con el nivel municipal de gobierno, siendo

(13) El relevamiento fue llevado a cabo en el mes de mayo de 2020. 
este un dato revelador. Por su parte, un conjunto de provincias ha brindado una jerarquía prioritaria a la problemática, disponiendo para la tarea de Secretarías de Estado (Buenos Aires, Córdoba, Chaco, Entre Ríos, Jujuy, La Pampa, Mendoza, Neuquén, Salta, Santa Cruz, Tucumán) o de Subsecretarías (Santa Fe, Misiones y Chubut), generalmente denominadas de asuntos municipales, o similares.

Otras provincias cuentan con oficinas de menor jerarquía abocadas a la problemática, tales como La Rioja (Dirección de Coordinación) y Río Negro (Dirección de Municipios). Finalmente, San Luis dispone de un Programa de Coordinación, mientras que un conjunto de provincias ni siquiera cuentan en sus organigramas con oficinas técnicas de vinculación con sus municipios (La Pampa, San Juan, Santa Cruz y Tierra del Fuego).

El análisis de las características de estas dependencias, los programas que ejecutan o las capacidades institucionales existentes en ellas exceden las posibilidades de este trabajo. No obstante, de un relevamiento normativo y organizacional identificamos solamente 5 provincias que cuentan con espacios de coordinación intergubernamental en materia fiscal en donde los municipios participan en la deliberación y la toma de decisiones (Córdoba, Misiones, Santa Fe, Catamarca y Chubut).

Córdoba cuenta con dos interesantes experiencias de articulación intergubernamental con la Unidad de Trabajo provincia-municipios y la Unidad de Trabajo provincia-comunidades regionales, espacios en donde participan representantes del gobierno provincial e intendentes y que han servido para la planificación de programas y de debate de propuestas que posteriormente tomaron trámite legislativo. Misiones tiene un Programa de Relación Fiscal con los municipios en sede del Ministerio de Hacienda, Finanzas, Obras y Servicios Públicos. Santa Fe dispone de una Comisión Provincial de Coordinación Fiscal, creada por decreto provincial No 1477/2008. Catamarca cuenta en su Subsecretaría de Asuntos Municipales con una Comisión de Participación Municipal, de conformación mixta, que gestiona los Fondos de Desarrollo y de Emergencia Municipal. Finalmente, Chubut tiene un Consejo Provincial de Responsabilidad Fiscal (lo componen el Ministro de Economía y los Secretarios de Economía municipales), creado por la ley 5257.

La mayoría de estos espacios nacen de la mano de los acuerdos fiscales multilaterales Nación-provincias, a los que las mismas han adherido, y se centran en los compromisos de responsabilidad fiscal y saneamiento de deudas, más que en la coordinación fiscal y tributaria propiamente dicha, configurando de todos modos interesantes y novedosas instancias de coordinación intergubernamental en el federalismo argentino. 
Estas escasas experiencias ponen en evidencia la baja relevancia que se brinda a la problemática en los gobiernos provinciales, y cómo la decisión técnica mayoritariamente excluye a los actores territoriales de mayor proximidad.

\section{Consideraciones finales}

El diseño federal contemplado en la última reforma constitucional argentina dio lugar, en términos normativos, a la configuración de un gobierno multinivel moderno y complejo, con miras a dar respuesta a los innumerables desafíos actuales y futuros asociados a la gestión de los territorios. Principios como la coordinación, solidaridad, desarrollo armónico y equilibrado del territorio, que constituyen la base del diseño federal, tras veintiséis años, siguen siendo desatendidos.

La ausencia de un pacto fiscal federal entre la Nación, las provincias y la Ciudad Autónoma de Buenos Aires que responda a las exigencias del mandato constitucional, como así también la inexistencia de un entramado de vínculos institucionalizados con reglas claras y estables entre los diferentes niveles de gobierno, torna al federalismo argentino en un juego de poder sin reglas formales estables. El estado de cosas empuja hacia una informalización de las RIG y a una personalización del vínculo entre quien pide y quien otorga, factores altamente distorsivos de un diálogo federal consolidado. Tales aspectos, evidentes en el vínculo entre la Nación y provincias, se observan también en los vínculos entre las provincias y sus gobiernos locales, en mayor o menor medida.

Otro importante aspecto que contribuye a que el capítulo federal de la reforma constitucional de 1994 sea hoy una promesa incumplida es la falta de reconocimiento de parte de algunas constituciones provinciales del régimen de la autonomía municipal.

En primer lugar, si concebimos a la autonomía municipal como un requisito previo y necesario para el desarrollo de vínculos interjurisdiccionales consistentes, es menester armonizar las constituciones provinciales al mandato de la $\mathrm{CN}$, sobre todo en distritos de máxima relevancia poblacional y política como lo son Santa Fe, Mendoza y Buenos Aires. También es un debate pendiente la definición de los alcances y límites de la autonomía municipal, ya que la viabilidad financiera de los mismos es necesaria para construir un federalismo de bases sólidas.

En segundo lugar, y vinculado a los alcances y contenidos de la autonomía municipal, un aspecto a considerar son las amplias limitaciones al ejercicio de la potestad tributaria local en nuestro federalismo subnacional. A la par de ello, y de un modo preocupante, destacamos la insuficiencia de instancias y mecanismos de coordinación intergubernamentales en materia fiscal entre provincias y municipios, lo que contribuye al deterioro y precariedad de los vínculos 
intergubernamentales y conduce a vehiculizar tales relaciones por mecanismos de negociación informales y discrecionales.

Un tercer elemento evidenciado es la asimetría de los porcentajes de recursos federales que las provincias distribuyen a sus municipios, siendo esta disparidad muy significativa entre aquellas jurisdicciones que más y menos recursos destinan a la gestión municipal, como se analiza en el punto IV.2. A ello se añade otra diferencia considerable con respecto a las competencias tributarias que las constituciones provinciales reconocen a los gobiernos locales y las alícuotas de los tributos internos provinciales que se coparticipan.

Finalmente, existen en nuestro país escasísimas instancias de coordinación en materia fiscal con participación mixta provincial-municipal. Las cinco excepciones identificadas fueron reseñadas en el punto IV.4, justificando nuestra hipótesis acerca de una baja densidad de RIG institucionalizadas y, en consecuencia, una fuerte primacía de la toma de decisiones en ámbitos del gobierno provincial (ejecutivo y legislativo).

Otro dato de interés se vincula con las características de las oficinas provinciales dedicadas a la coordinación de políticas con los municipios. En muchas provincias no existen como tales, siendo dichas funciones subsumidas por otras dependencias. En otras, son oficinas de menor relevancia, y solamente algunas provincias jerarquizan las mismas con un rango de Secretaría de Estado o similar. Esto también desnuda la debilidad del diálogo técnico calificado entre las burocracias provinciales y municipales, el que seguramente se caracterizará por las asimetrías de capacidades institucionales y de poder de negociación.

El conjunto de estos factores hace que las decisiones en materia fiscal se efectúen dentro de los poderes ejecutivo o legislativo provinciales, según corresponda, y que los municipios generalmente no formen parte del proceso de construcción de la política. Junto con ello, la ausencia de instancias formales de deliberación común entre burocracias especializadas hace que los vínculos se vuelvan personalizados e informales, entre gobernadores e intendentes, o entre funcionarios de ambos niveles gubernamentales. Dicha situación de informalidad genera una posición de debilidad intrínseca de los gobiernos locales por la que transitan las relaciones provincia-municipios en la mayor parte de las jurisdicciones del federalismo argentino.

La decisión metodológica de comparar el conjunto de las provincias genera la dificultad de profundizar en experiencias o casos particulares, dado el volumen de información que ello conlleva. No obstante, los elementos obtenidos permiten corroborar nuestra afirmación apriorística acerca del escaso volumen de las RIG provincia-municipios en el país, la heterogeneidad de los casos, las fuertes 
asimetrías materiales y simbólicas que las caracterizan y, frente a ello, la primacía de vínculos informales y negociaciones personalizadas entre gobernadores e intendentes, donde estas asimetrías quedan al descubierto.

Aun evitando generalizar, creemos que es preciso avanzar en la consolidación de las RIG en nuestro federalismo como condición necesaria de su fortalecimiento institucional. La agenda prioritaria del federalismo argentino exige la existencia normativa de un acuerdo fiscal federal y, de la mano con ello, una multiplicación de las instancias de coordinación y articulación de políticas multinivel en los términos propuestos por la Constitución Nacional.

\section{Bibliografía}

Astarita, M.; Bonifacio, S. y Del Cogliano, N. (2012). Relaciones intergubernamentales (RIGS) en la administración pública Argentina. En J. M. Abal Medina y H. Cao, Manual de la nueva administración pública Argentina. Buenos Aires: Editorial Ariel.

Bernal, M. (2015). Federalismo, Relaciones Intergubernamentales y Gobierno Multinivel en Argentina a veinte años de la reforma constitucional de 1994. En M. Bernal; C. Pizzolo y A. Rossetti (coord.), ¿Que veinte años no es nada! Un análisis crítico de la reforma constitucional de 1994 en Argentina. Buenos Aires: Eudeba.

Bernal, M y Pucheta, N. (2017). Implicancias institucionales, políticas y financieras de la ausencia de un Pacto Fiscal en el federalismo argentino. Revista Jurídica de la Universidad Autónoma de Madrid, No 36 (pp. 51-74). Recuperado de https://revistas.uam.es/revistajuridica/article/view/9349

Bernal, M. (2018). El federalismo argentino: Entre lo viejo que no termina de regir y lo nuevo que no termina de nacer. En M. Bernal y C. Pizzolo (Ed.), Modelos para armar. Procesos federales actuales, descentralización del poder y desafios del gobierno multinivel. Córdoba: Ed. Astrea y Editorial de la Universidad Nacional de Córdoba.

Bidart Campos, G. (1996). Manual de la Constitución reformada. Buenos Aires: Ediar.

Escolar, M. (2011). Relaciones intergubernamentales, fragmentación política y federalismo ejecutivo. El caso argentino. Trabajo presentado en el $X$ Congreso Argentino de Ciencia Política: Democracia, integración y crisis en el nuevo orden global. Tensiones y desafíos para el análisis político. SAAP y Universidad Católica de Córdoba. Córdoba, 27 al 30 de julio. 
Friedrich, C. J. (1968). Trends of federalism in theory and practice. Londres: Pall Mall.

Hernández, A. M. (2019). Estudios de federalismo comparado. Argentina, Estados Unidos y México. Buenos Aires: Rubinzal Culzoni.

Pontifes Martínez, A. (2002). Relaciones Intergubernamentales. Gaceta Mexicana de Administración Pública Estatal y Municipal, No 65 (pp. 43-59). México: UNAM.

Rezk, E.; Padraja Chaparro, F. y Suárez Pandiello, J. (2011). Coparticipación impositiva argentina y financiación autonómica española: un estudio de federalismo fiscal comparado. Buenos Aires: Consejo de Ciencias Económicas de la Ciudad Autónoma de Buenos Aires.

Teijeiro, M. (2009). El federalismo fiscal. Disertación ante el Instituto de Ética y Política Económica de la Academia Nacional de Ciencias Morales y Políticas de Argentina. Recuperado de http://www.ancmyp.org.ar/user/files/04Teijeiro.pdf

Watss, R. (2006). Sistemas federales comparados. Barcelona: Marcial Pons.

\section{Jurisprudencia}

CSJN, "Provincia de San Luis c/ Estado Nacional s/acción declarativa de inconstitucionalidad y cobro de pesos", 24/11/2015.

CSJN, "Provincia de San Luis c/ Estado Nacional y otra s/cobro de pesos", $24 / 11 / 2015$.

CSJN, "Córdoba, provincia de c/ Estado Nacional y otro s/Medida cautelar", $24 / 11 / 2015$.

CSJN, "Rivademar, Ángela Martínez Galván de c/ Municipalidad de Rosario", 1989.

CSJN, “Bazán, Fernando s/ amenazas”, 4/04/2019.

Fecha de recepción: 31-03-2020 Fecha de aceptación: 25-08-2020 